\title{
PERCEPÇÃO DA POPULAÇÃO QUANTO A ARBORIZAÇÃO COM Mangifera indica L. (MANGUEIRA) NAS RUAS DE BELÉM - PA
}

\author{
PERCEPTION OF THE POPULATION CONCERNING THE AFFORESTATION \\ WITH Mangifera indica L. (MANGO TREE) IN THE STREETS OF BELÉM - PA
}

\author{
Dâmaris Araújo da Silva¹, Daniela Biondi Batista², Antônio Carlos Batista ${ }^{3}$
}

\section{RESUMO}

O objetivo desta pesquisa foi avaliar a percepção dos moradores do Distrito Administrativo de Belém (DABEL) em relação à arborização viária com Mangifera indica. A metodologia consistiu na aplicação de entrevistas aos moradores do DABEL a fim de avaliar o grau de satisfação quanto à arborização com Mangifera indica e o nível de envolvimento na manutenção dessa espécie pelos mesmos. Foram entrevistadas 304 pessoas no DABEL, sendo que $54 \%$ são do gênero feminino; $51 \%$ possui nível superior; $87 \%$ dos entrevistados preferem a Mangifera indica na arborização viária; $42 \%$ salientaram todos os principais benefícios proporcionados pela Mangifera indica; $70 \%$ dos entrevistados perceberam danos relacionados à injúria no caule e danos às raízes; $22 \%$ colaboram com a manutenção das $\mathrm{m} ; 53 \%$ das pessoas sugeriram a prática de poda nas árvores. Quanto ao reconhecimento como "Cidade das mangueiras", $74 \%$ dos entrevistados acreditam que esse título é válido. Recomenda-se desenvolver uma maior sensibilização da população buscando o comprometimento da mesma, visando uma melhor qualidade de vida e a preservação da Mangifera indica.

Palavras-chave: Percepção ambiental; Arborização urbana; Árvore frutífera.

\section{ABSTRACT}

The main goal of this research was to evaluate the perception of the (DABEL) residents' about the afforestation with Mangifera indica. The methodology consisted of applying interviews with residents of DABEL to assess the degree of satisfaction with the afforestation with Mangifera indica and the level of involvement in the maintenance of the specie by the same. There were interviewed 304 people in DABEL and $54 \%$ are female. Regarding to education, $51 \%$ have a graduation degree. Concerning the preference for Mangifera indica, $87 \%$ of interviewed prefer this specie at the street afforestation. Almost $90 \%$ said being capable to identifying the species. About the benefits provided by Mangifera indica, $42 \%$ of people know all the key benefits described in the worksheet. As for the damage, $70 \%$ of interviewed observed damages in the stem and in the roots. Concerning to cooperation in the maintenance of Mangifera indica, 22\% of interviewed said they collaborate. About recommendations, $53 \%$ of people suggested the practice of pruning. As for Belém to be recognized as "the city of the mango trees", $74 \%$ of interviewed believe that this title is valid. It is recommended to develop a greater awareness of the population, seeking the commitment of the same, to improve the quality of life and the preservation of Mangifera indica.

Key-words: Environmental awareness; Urban forest; Fruitful tree.

\footnotetext{
Recebido em 28.06.2015 e aceito em 01.09.2015

1 Engenheira Florestal, MSc., Doutoranda em Engenharia Florestal na Universidade Federal do Paraná. Curitiba/PR Email: damarislevita11@yahoo.com.br

2 Engenheira Florestal, Dra., Professora da Universidade Federal do Paraná, Curitiba/PR E-mail: dbiondi@ufpr.br

3 Engenheiro Florestal, Dr., Professor da Universidade Federal do Paraná, Curitiba/PR E-mail: batistaufpr@ufpr.br
} 


\section{INTRODUÇÃO}

O estudo da percepção ambiental é de fundamental importância à gestão da arborização urbana (MELLAZO, 2005; QUADROS; FREI, 2009), pois o ser humano tende a revelar suas expectativas, anseios, julgamentos e condutas com relação às árvores no meio urbano. Canabrava et al. (2007) afirma que essas pessoas são os primeiros a notarem o impacto na qualidade ambiental, devido ao uso direto e constante de seus recursos.

A relação da população paraense com o plantio de Mangifera indica L. (mangueira) na arborização viária é muito antiga, tem mais de cem anos de existência. Segundo Porto et al. (2014), a Mangifera indica na arborização urbana de Belém tem grande importância no meio sociocultural, por isso foram tombadas pelo patrimônio histórico e consideradas um bem de uso comum e de preservação permanente e, também, deu o título à Belém de "Cidade das mangueiras", devido a repercussão nacional sobre a abundância de Mangifera indica nas ruas da cidade.

A Mangifera indica foi a espécie que mais se destacou na arborização de Belém por atender perfeitamente a problemática ambiental da cidade ao criar um microclima agradável, paisagem contemplativa e viridente, bem-estar significativo, formação de túneis verdes nas ruas e avenidas da cidade, além de ter rápido crescimento, folhagem densa e beneficiar com uma ampla sombra (LOUREIRO; BARBOSA, 2010).

De acordo com Lorenzi et al. (2006), a Mangifera indica é uma espécie frutífera originária das Ásia, sendo que a maior parte é produzida em países em desenvolvimento como Índia, Paquistão, México, Brasil e China. É uma árvore frondosa e perenifólia, que pode atingir até $30 \mathrm{~m}$ de altura. Possui copa globosa, densa de até $25 \mathrm{~m}$ de diâmetro, com folhas jovens aromáticas, subcoriáceas, simples e alternas. Apresenta fruto do tipo drupa, de peso variável de menos de $100 \mathrm{~g}$ a mais de $1 \mathrm{~kg}$.

Oliveira e Corona (2008) definem que a percepção ambiental está relacionada ao significado da representação que um indivíduo tem sobre o seu ambiente e a correlação com seus valores, interpretações e conhecimentos acumulados dos processos vitais.

Rodrigues et al. (2010) afirmam que é comum o fracasso dos plantios ou da manutenção da arborização urbana. Isso se deve principalmente à falta da participação comunitária e da ausência de conscientização sobre a importância da arborização, fazendo necessário que as ações ambientais envolvam a população para um eficiente planejamento e manutenção da arborização.

Como exemplos de trabalhos de percepção ambiental que tratam da análise da arborização urbana pode-se citar os seguintes autores: Rodrigues et al. (2010), Gross et al. (2012), Pizziolo et al. (2014) e Zem e Batista (2014). 
É preciso, portanto, salientar a importância de trabalhos sobre a percepção ambiental da população que objetivam verificar in loco a opinião da mesma, pois essas irão colaborar com dados importantes para a gestão da arborização urbana, buscando a melhoria da qualidade das condições ambientais e das relações humanas (FERREIRA; AMADOR, 2013).

Neste contexto, o estudo teve como objetivo avaliar a percepção dos moradores do Distrito Administrativo de Belém (DABEL) em relação à arborização viária com Mangifera indica com o intuito de subsidiar ações de manejo e plantio da espécie.

\section{MATERIAL E MÉTODOS}

Esta pesquisa foi realizada no Distrito Administrativo de Belém - PA (DABEL), conforme mostra a Figura 1. O DABEL está localizado no município de Belém, inserida na porção oeste do estado do Pará, entre as coordenadas $01^{\circ} 27^{\prime} 20^{\prime \prime}$ de latitude sul e $48^{\circ} 30^{\prime}$ 15 " de longitude oeste (SECRETARIA MUNICIPAL DE COORDENAÇÃO GERAL DO PLANEJAMENTO E GESTÃO - SEGEP, 2012).

O clima é classificado como Afi (quente e úmido), segundo a classificação de Köppen, considerado como clima de floresta tropical, com ausência de estação fria e temperatura média anual igual a $25^{\circ} \mathrm{C}$. A precipitação média anual é de $2.834 \mathrm{~mm}$. O relevo é caracterizado pelos baixos platôs e planícies litorâneas, fazendo parte do Baixo Amazonas com altitude média de $4 \mathrm{~m}$, sofrendo influência das marés altas e tendo dificuldade no escoamento das águas da chuva (SEGEP, 2012).

A vegetação compõe-se de florestas secundárias ou capoeiras que substituíram a antiga Floresta Densa dos baixos platôs, entremeada por fragmentos de mangues e siriubais, que domina os tratos marginais dos cursos D'água e as baixadas, onde prevalecem formações herbáceas, subarbustivas e arbustivas (SEGEP, 2012).

O DABEL localiza-se na zona centro sul, considerada área nobre do município de Belém (INSTITUTO BRASILEIRO DE GEOGRAFIA E ESTATÍsTICA - IBGE, 2012). Apresenta uma área de 13.697.605,48 $\mathrm{m}^{2}$ com 144.948 habitantes, limitando-se com os distritos de Sacramenta, Entroncamento e Guamá. O distrito é composto pelos seguintes bairros: Reduto, Campina, Nazaré e parte dos bairros do Marco, Umarizal, São Brás, Guamá, Cremação, Batista Campos, Cidade Velha, Jurunas e Canudos (SEGEP, 2012).

Segundo Gusmão (2014), o DABEL engloba os bairros mais nobres da capital paraense, representando a área mais valorizada da cidade devido à concentração de serviços e áreas verdes. Para Luz e Rodrigues (2014), o DABEL é composto pelos bairros 
pioneiros no processo de arborização, de maior adensamento urbano, concentração vertical (prédios), horizontal (casas), de serviços e possui o maior número de praças.

O DABEL foi selecionado nesta pesquisa por ser a área que apresenta uma urbanização consolidada e concentra os bairros que detém a maioria da arborização com Mangifera indica da cidade de Belém.

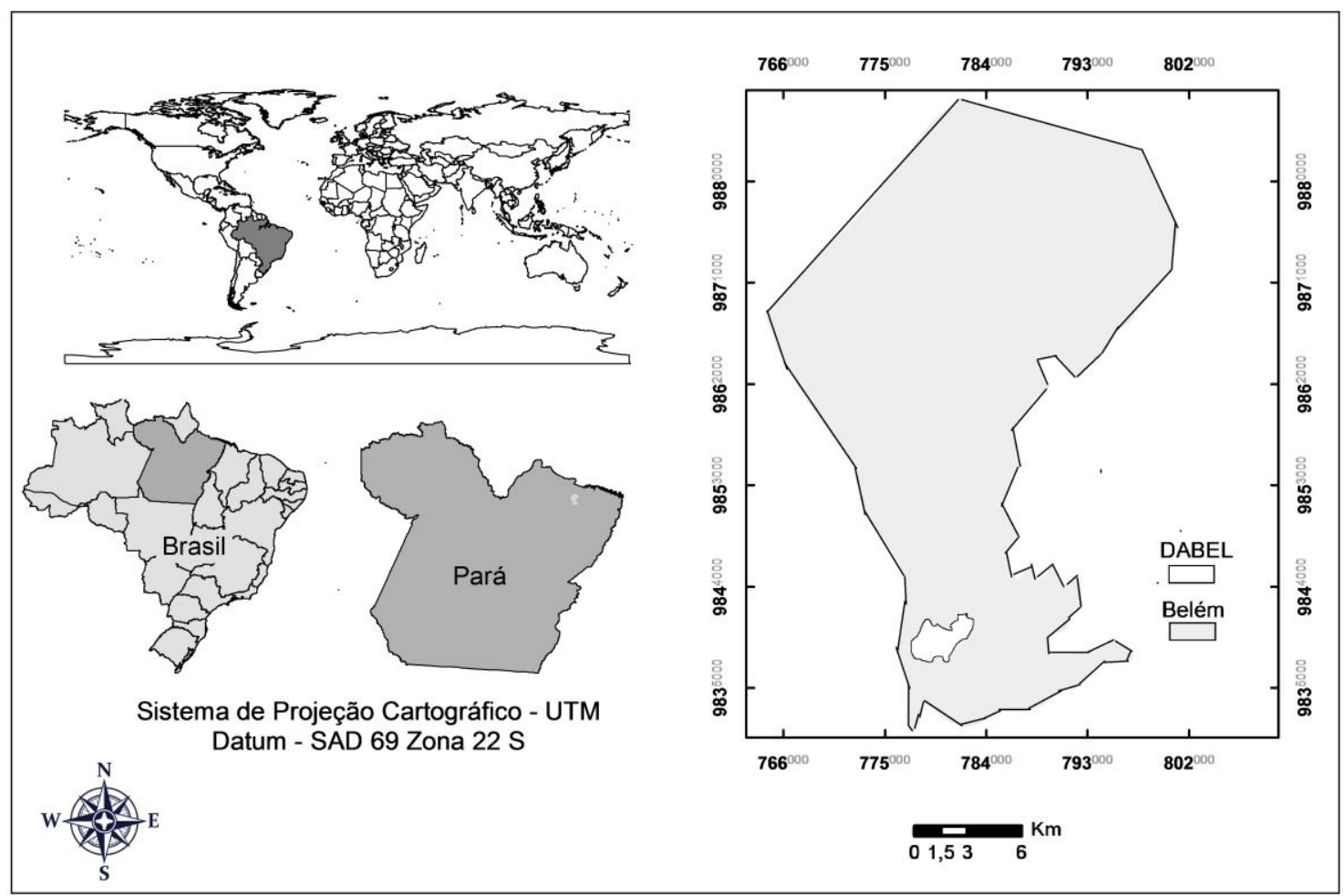

Figura 1. Localização geográfica da cidade de Belém com destaque para o DABEL

Figure 1. Geographic location of Belém city, highlighting DABEL

A avaliação da percepção dos moradores do DABEL foi realizada no mês de maio de 2014. Foram aplicadas entrevistas semi-estruturadas (Quadro 1), divididas em duas questões abertas, em que requer uma opinião do entrevistado e sete questões fechadas, em que requer uma resposta direta e limitada.

Foram coletadas opiniões de $11 \%$ dos residentes e/ou comerciantes que tinham arborização com Mangifera indica nos bairros do DABEL, totalizando 304 entrevistados. Segundo Alreck e Settle (2004), nas pesquisas tipo survey, uma amostra composta por 300 respondentes já traz níveis estatísticos satisfatórios de confiança e erro amostral, com confiança de $95 \%$ e erro menor do que $10 \%$ em relação à média real da população, independentemente do tamanho da população. Acima desta quantidade, não há uma diminuição significativa do erro e a pesquisa se torna pouco vantajosa em termos de custobenefício. 
Como critério para as entrevistas foi estabelecido que o entrevistado tivesse a idade superior a 16 anos, independente de gênero e que em frente a sua casa existisse uma Mangifera indica.

Quadro 1. Formulário de avaliação da percepção ambiental quanto à Mangifera indica L. (mangueira) no DABEL

Board 1. Evaluation form of environmental awareness regarding to Mangifera indica L. (mango trees) at DABEL

Universidade Federal do Paraná
\[ \text { Curso de Pós-graduação em Engenharia Florestal } \]
Pesquisa: Avaliação da percepção ambiental quanto à Mangifera indica L. (mangueira) no
DABEL
Data: / /
1) Localização das mangueiras
Si - situação do imóvel: ( ) aberto ( ) fechado
Fc - função do imóvel: ( ) residência ( ) comércio
2) Perfil dos entrevistados
2.1 sexo: ( ) masculino ( ) feminino
2.2 escolaridade: ( ) fundamental ( ) médio ( ) superior ( ) sem instrução
3) Você prefere a sua rua arborizada com mangueira? ( ) sim ( ) não
4) Quais os benefícios fundamentais da mangueira para sua rua?
( ) qualidade de vida ( ) purificação do ar ( ) sombra ( ) abrigo e alimento para avifauna
( ) beleza ( ) todas as alternativas ( ) sem resposta
5) Você consegue reconhecer uma mangueira em sua rua? ( ) sim ( ) não
6) Você colabora com a manutenção das mangueiras em Belém? ( ) sim ( ) não
6.1- Caso sim, de que forma colabora?
( ) morte provocada ( ) tutor arrancado ( ) danos nas raízes ( ) anelamento
8) que você recomendaria para melhoria da arborização da rua?

Posteriormente, os dados coletados foram processados em planilha do aplicativo Microsoft Excel 2007 e os resultados apresentados em percentagem e gráficos. 


\section{RESULTADOS E DISCUSSÃO}

Foram entrevistados moradores de 304 imóveis nos 11 bairros amostrados (Guamá, Cidade Velha, Reduto, Jurunas, Marco, Cremação, Campina, São Brás, Umarizal, Batista Campos e Nazaré), dos 12 que compõe o Distrito de Belém. O bairro Canudos não foi amostrado nesta pesquisa, pois não existem indivíduos de Mangifera indica em suas ruas.

Foram aplicadas 267 entrevistas em residências (88\%) e 37 entrevistas em locais comerciais (12\%).

Na Figura 2 observa-se a situação do imóvel nos bairros do DABEL no momento em que foram avaliados.

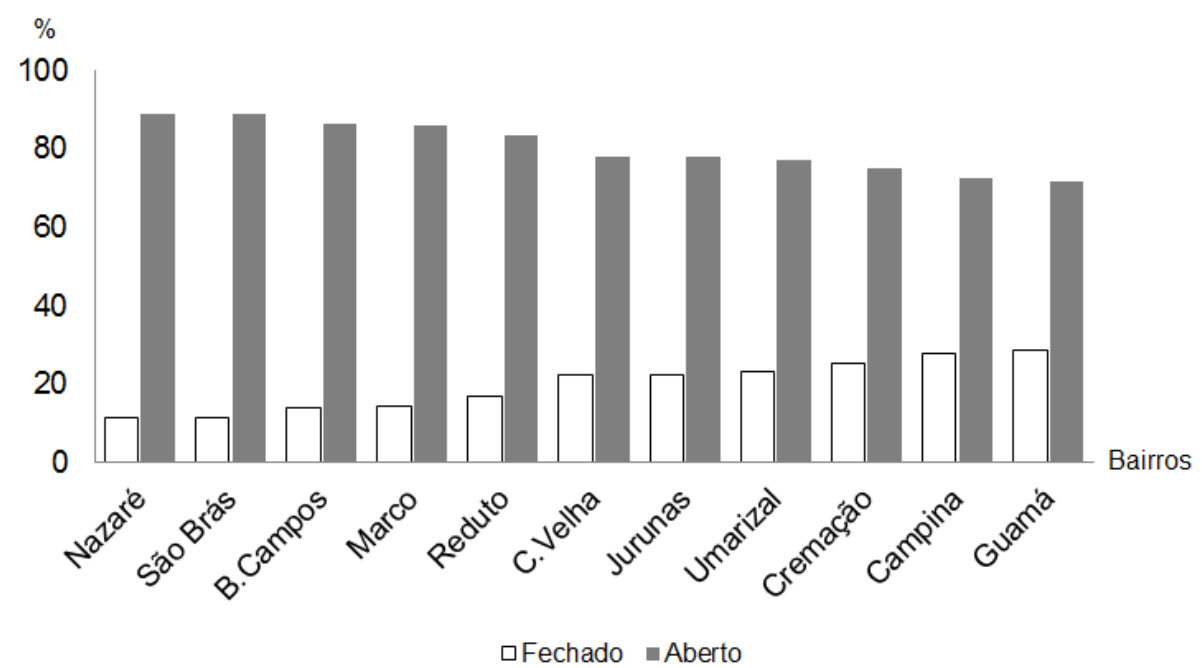

Figura 2. Situação do imóvel nos bairros do DABEL

Figure 2. Property situation at DABEL neighborhoods

Observa-se que entre os bairros, destacou-se o bairro Nazaré com a maioria dos imóveis em funcionamento ou abertos e totalizando 89\%; e o bairro Guamá com a maior porcentagem de imóveis desativados ou fechados, totalizando $29 \%$.

Em relação aos bairros que apresentaram a maioria dos imóveis caracterizados como residenciais, destacaram-se os bairros Guamá e Cremação, ambos totalizando 100\%, e o bairro com maior índice de estabelecimentos comerciais foi São Brás com 27\% (Figura 3). 


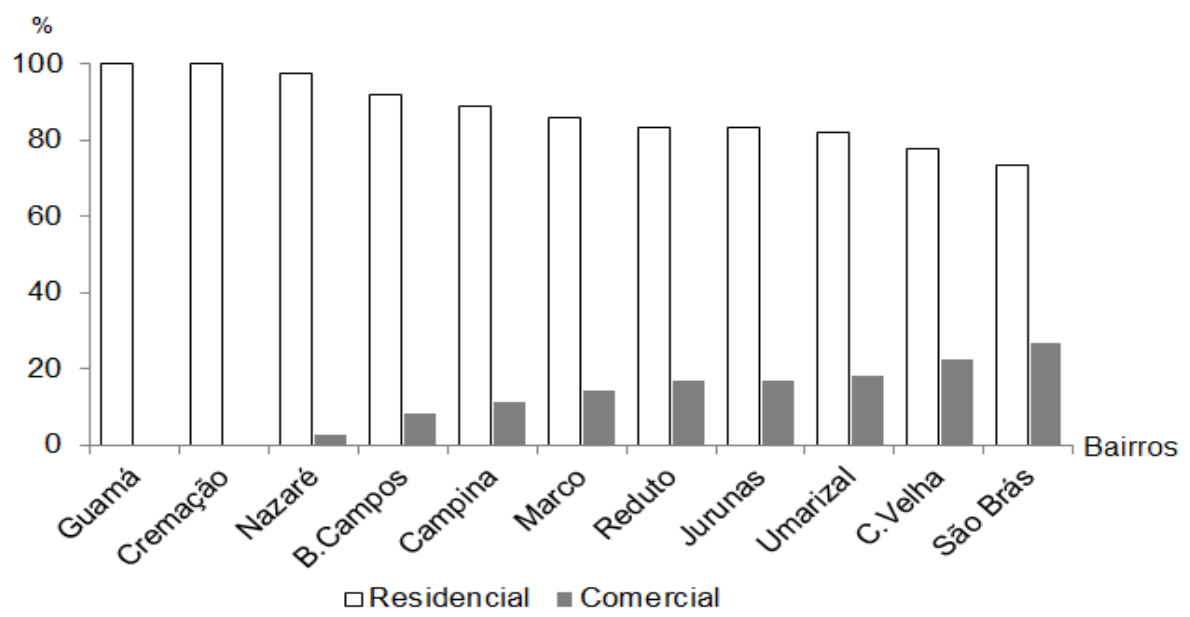

Figura 3. Função do imóvel nos bairros do DABEL

Figure 3. Property function at DABEL neighborhoods

Percebeu-se que o bairro Nazaré possui uma infraestrutura consolidada, por apresentar rede de abastecimento de água e esgoto, sistema viário, energia elétrica e recolhimento e tratamento de resíduos sólidos urbanos, ao contrário dos bairros Guamá e Cremação que se caracterizaram pela carência dessa infraestrutura e uso predominantemente residencial. Essas características dos bairros estão de acordo com as definições de zoneamento da cidade de Belém, destacada pela Lei Municipal no 8.655 , de 30 de julho de 2008, que trata da promoção de desenvolvimento urbano, zoneamento, uso e ocupação do solo, sistema viário e integra o sistema de planejamento municipal (SEGEP, 2012).

Assim, a vegetação urbana pode estar comprometida em locais de ocupação mais intensa, como nos bairros do Jurunas, Guamá e Cremação. Isso ocorre devido à implantação de novas residências e pontos comerciais, que exercem forte pressão imobiliária sobre a arborização urbana.

Na Figura 4 é apresentado o gênero dos entrevistados dos bairros do DABEL.

Dos 304 entrevistados nos bairros, 165 eram do gênero feminino (54\%) e 139 do gênero masculino (46\%).

O bairro com maior índice de mulheres entrevistadas foi o Guamá, totalizando $71 \%$, e o bairro da Cremação foi o que apresentou $50 \%$ do gênero masculino e $50 \%$ do gênero feminino. 


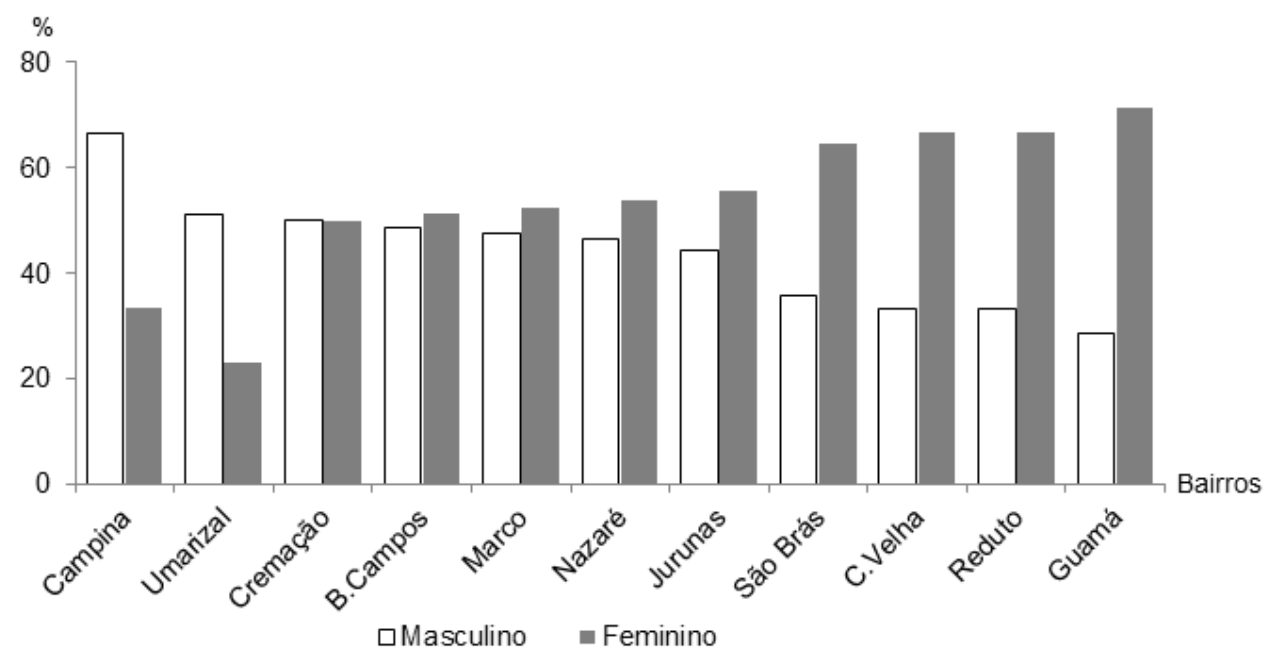

Figura 4. Gênero dos entrevistados nos bairros do DABEL

Figure 4. Gender of interviewed residents at DABEL neighborhoods

Com relação à escolaridade da população amostrada, a maioria possui nível superior, seguido de nível médio e nível fundamental, com 51, 35 e 14\%, respectivamente. Não foi observado nenhum entrevistado sem instrução (Figura 5).
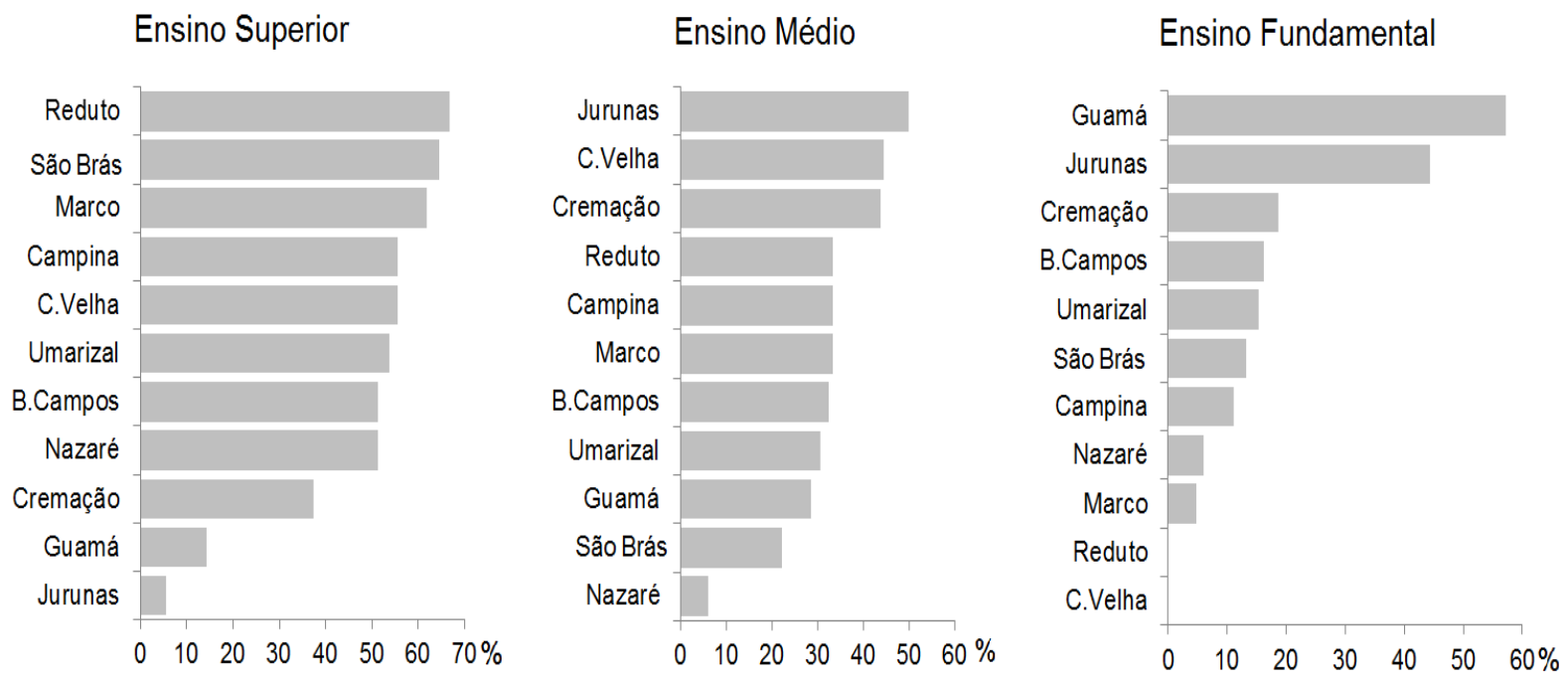

Figura 5. Escolaridade dos entrevistados nos bairros do DABEL

Figure 5. Educational level of interviewed residents at DABEL neighborhoods

Os bairros Umarizal, São Brás e Marco foram os que apresentaram maior percentual de instrução escolar, enquanto que os bairros Jurunas, Guamá e Cremação foram o que obtiveram menor grau de escolaridade, predominando ensino fundamental. Esses resultados podem estar relacionados ao histórico de criação desses bairros, marcados pela carência de infraestrutura, equipamentos públicos e falta de investimento. 
De acordo com os resultados da pesquisa, observa-se que é bastante variável a escolaridade dos entrevistados, evidenciando-se que as diferentes classes da população foram representadas na pesquisa.

Nas Figuras 6 e 7 estão representadas as questões relacionadas à percepção dos entrevistados quanto à preferência e identificação da Mangifera indica nos bairros do DABEL.

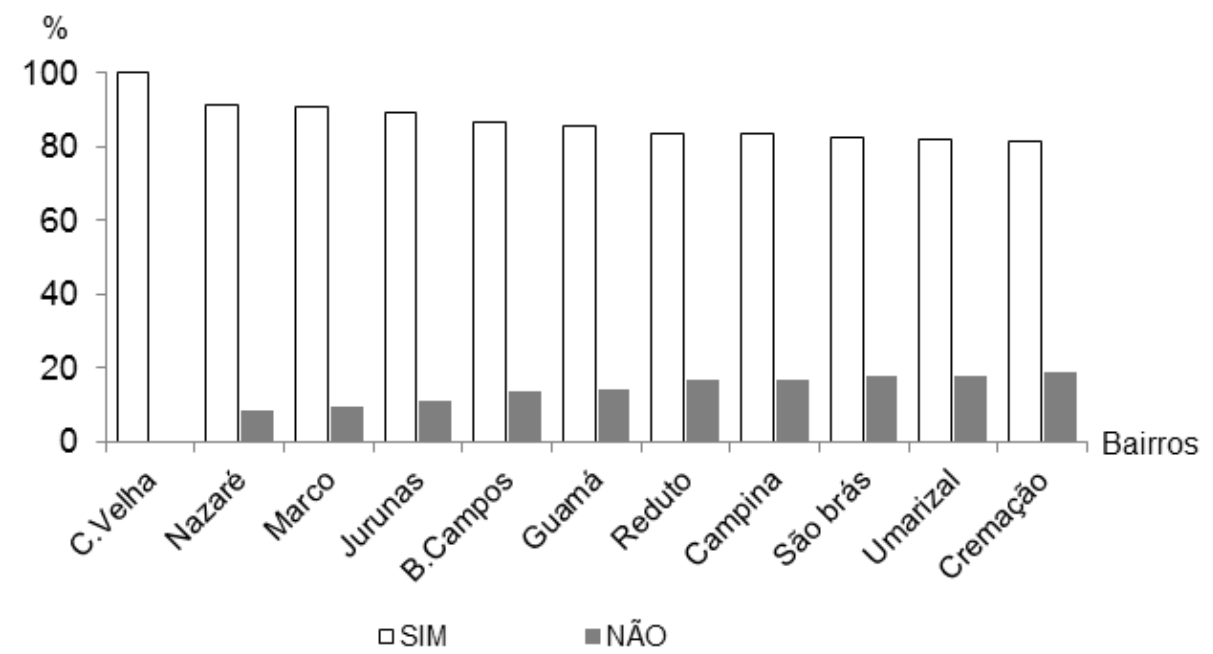

Figura 6. Percepção dos entrevistados quanto à preferência da arborização pela Mangifera indica L. (mangueira) nos bairros do DABEL

Figure 6. Perception of interviewed residents regarding the preference for afforestation with Mangifera indica L. (mango tree) at DABEL neighborhoods

De maneira geral, percebe-se que todos os moradores dos bairros apresentaram preferência predominante pela Mangifera indica em suas ruas (87\%). Os moradores do bairro Cidade Velha foi o que mais apresentou preferência pela arborização viária com a mangueira, totalizando $100 \%$. Isso ocorre devido ser o bairro mais antigo, preservar muito a história da arborização com Mangifera indica e seus benefícios para a cidade de Belém.

Nota-se que a Mangifera indica ainda é a espécie favorita pela população no cenário urbano paraense. Segundo Loureiro e Barbosa (2010), de modo geral, a população paraense, historicamente, tem preferência pela Mangifera indica, por esta apresentar copa larga e proporcionar sombreamento e bem-estar. Além disso, existem pessoas que fazem da manga uma fonte temporária de renda nas épocas de safra, que geralmente se prolonga entre os meses de dezembro e março, coincidindo com o período chuvoso. 


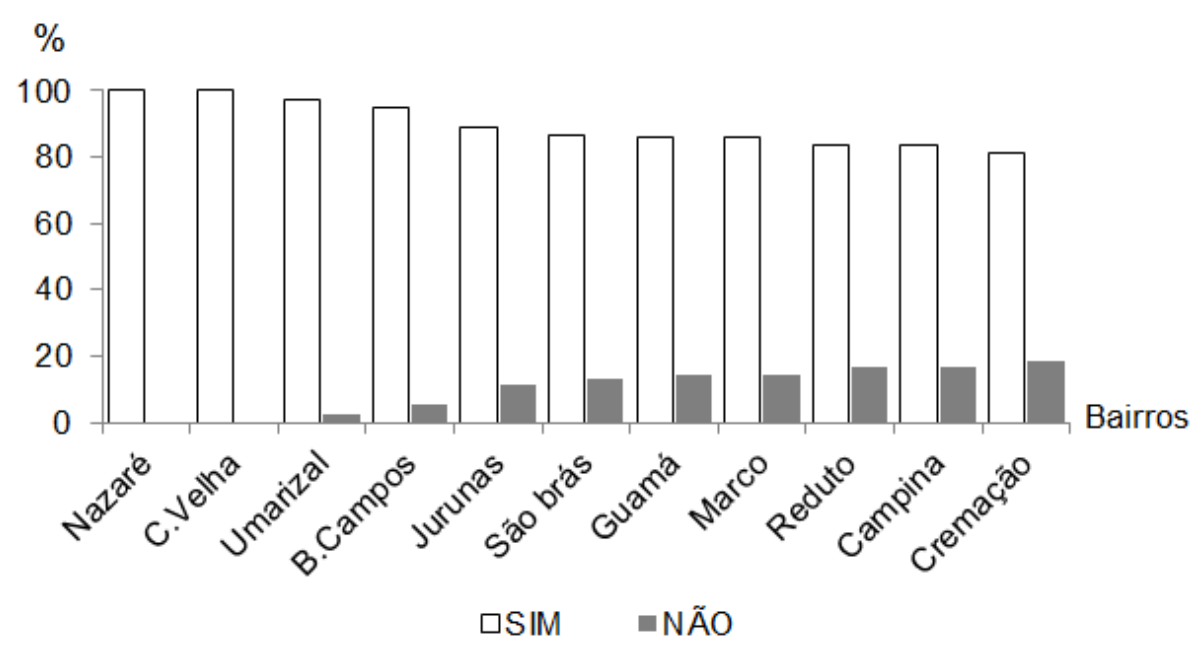

Figura 7. Percepção dos entrevistados quanto à identificação da Mangifera indica L. (mangueiras) nos bairros do DABEL

Figure 7. Perception of interviewed residents regarding the identification of Mangifera indica L. (mango tree) at DABEL neighborhoods

Em relação ao quesito "reconhecimento da mangueira plantada em sua rua" a maior parte dos entrevistados de todos os bairros reconheceram a espécie Mangifera indica plantada na sua rua (90\%). Embora tenha se constado altas percentagens de reconhecimento, os moradores e comerciantes entrevistados nos bairros Nazaré e Cidade Velha foram os que mais reconheceram a espécie plantada em sua rua (100\%).

Nesse contexto, os quesitos avaliados podem ser relacionados ao item de reconhecimento do título da cidade de Belém como a "Cidade das mangueiras". Dos 304 entrevistados, a maioria (74\%) afirma que Belém ainda é reconhecida como a "Cidade das mangueiras", por acreditarem na predominância do plantio de Mangifera indica L. nas ruas da capital paraense em relação às demais cidades brasileiras. Enquanto que $26 \%$ percebem que Belém não merece ser a detentora desse título, por esse plantio se concentrar apenas nos bairros Nazaré, Batista Campos e Umarizal, que compõe a área nobre da cidade.

Silva (2015) afirma que o título de "Cidade das mangueiras" foi dado à Belém há décadas, antes do período de 1960, quando a capital paraense registrou uma aceleração em sua ocupação. Ressalta-se ainda que o crescimento urbano não foi acompanhado do plantio de espécies de mangueira. Segundo o mesmo autor, foi constatado que a Mangifera indica representa a quarta espécie de árvore que predomina em Belém, ficando atrás das espécies: fícus (Ficus benjamina), oitizeiro (Licania tomentosa) e castanhola (Terminalia catappa).

Marialva (2006) afirma que Belém desempenha sua função de atrativo turístico a partir do seu título de "Cidade das mangueiras" que agrega seu rico patrimônio históricocultura e implica diretamente na vida social e cultural dos paraenses. 
Dessa forma, recomenda-se que se os moradores querem que a cidade mantenha o título de "Cidade das mangueiras", devem solicitar o plantio de mudas de Mangifera indica onde foram realizadas as retiradas e promover a expansão da área plantada de Mangifera indica. Esta expansão deverá, entretanto, ser realizada em locais que permitam o crescimento adequado da árvore.

Contudo, os moradores entrevistados apresentaram alto grau de percepção dos indivíduos de Mangifera indica, revelando que essa espécie é marcante no meio urbano e faz parte do dia-a-dia dos moradores do DABEL.

$\mathrm{Na}$ Figura 8 está apresentada a importância da Mangifera indica nos bairros do DABEL.

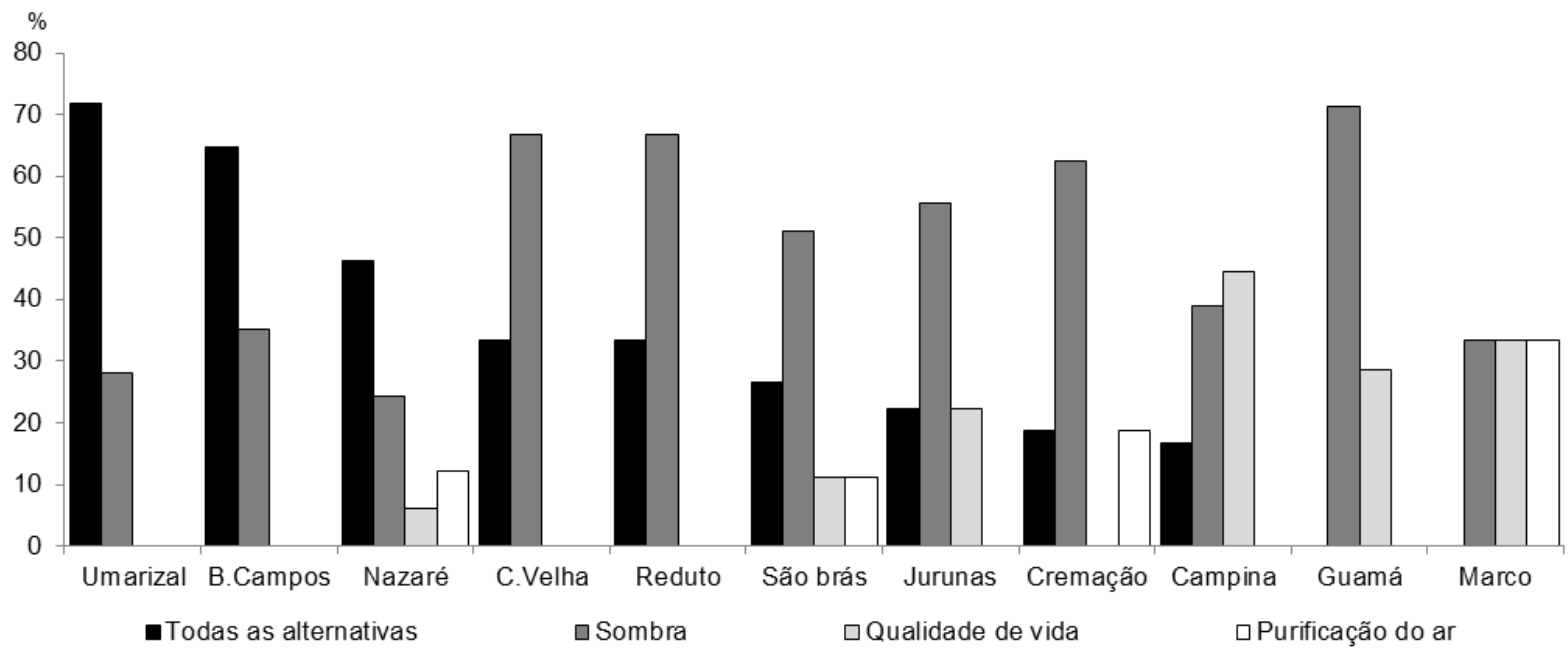

Figura 8. Percepção dos entrevistados quanto à importância da Mangifera indica L.(mangueira) nos bairros do DABEL

Figure 8. Awareness of interviewed residents regarding the importance of Mangifera indica L. (mango tree) at DABEL neighborhoods

Com relação à importância da Mangifera indica, 42\% dos entrevistados salientaram todos os itens descritos na enquete como sendo os principais benefícios proporcionados pelas árvores, os quais foram: qualidade de vida, purificação do ar, sombra, abrigo e alimento para avifauna e embelezamento da rua.

Nos bairros Umarizal e Batista Campos foram os que se destacaram quanto à importância da mangueira, com 72 e 65\% respectivamente, ressaltando como principais benefícios da arborização: a melhoria da qualidade de vida, a purificação do ar, a sombra, a possibilidade de fornecer abrigo e alimento para avifauna e o aspecto visual agradável para a população.

No bairro Nazaré e São Brás os entrevistados agruparam o maior número de funções importantes da Mangifera indica na cidade. Entre as principais funções da 
arborização urbana, segundo a opinião dos entrevistados do bairro Nazaré, destacaram-se qualidade de vida, purificação do ar, sombra, abrigo à avifauna, somando 54\%, e todas as alternativas com 46\%. Já no bairro São Brás, para $73 \%$ dos avaliados, qualidade de vida, purificação do ar e sombra, e todas as alternativas com $27 \%$.

De modo geral, o quesito referente a importância da arborização apresentou uma alta percepção, inclusive aos ligados diretamente ao microclima urbano, como: sombreamento e purificação do ar.

Na Figura 9 estão apresentadas as questões relacionadas à "colaboração na manutenção das mangueiras" nos bairros do DABEL.

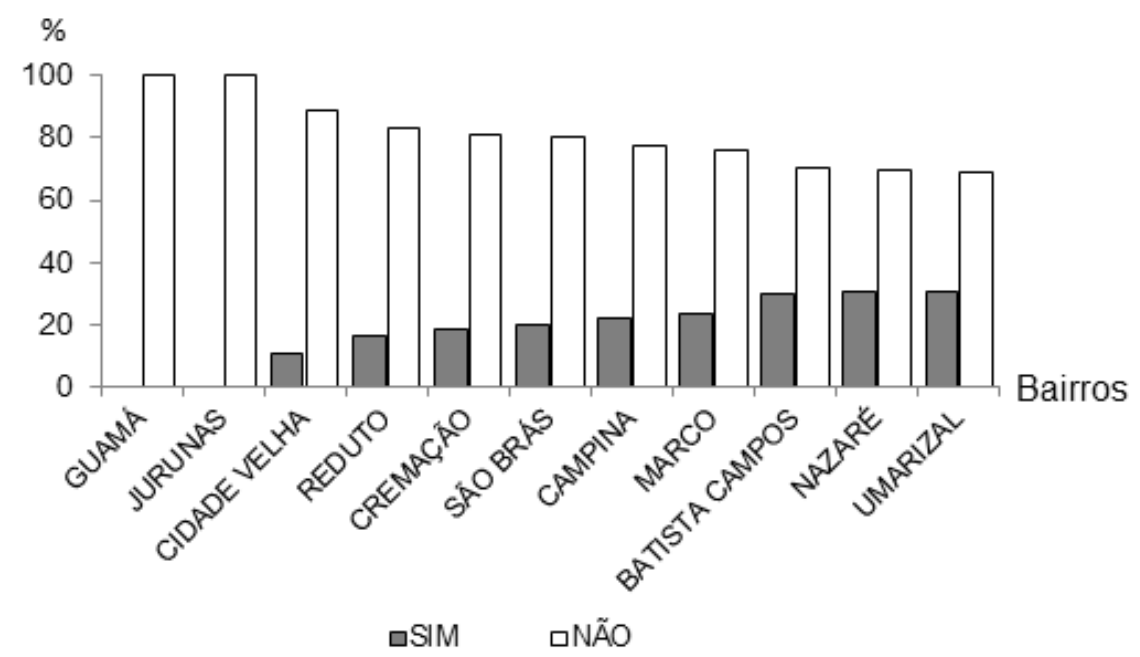

Figura 9 Percepção dos entrevistados quanto à colaboração na manutenção da Mangifera indica L. (mangueira) nos bairros do DABEL

Figure 9. Perception of interviewed residents regarding collaboration in the maintenance of Mangifera indica L. (mango tree) at DABEL neighborhoods

Em relação à percepção dos entrevistados quanto à "colaboração na manutenção das mangueiras", apenas $22 \%$ da população dos bairros participariam da manutenção de alguma forma, seja limpando o entorno da mangueira, ligando para Secretaria Municipal do Meio Ambiente (SEMMA) para realizar poda, ou recolocando tutores arrancados das árvores. Essa porcentagem é preocupante, pois demonstra que, apesar dos entrevistados perceberem os benefícios gerados pela arborização, os mesmos não se sentem responsáveis pela manutenção da Mangifera indica nas ruas.

Os bairros Umarizal, Nazaré e Batista de Campos foram os que mais se destacaram nesse item, em que $31 \%, 31 \%$ e $30 \%$ da população amostrada, respectivamente, respondeu que colabora para a manutenção da espécie Mangifera indica, por meio de ligações para SEMMA para realizar poda. Dessa forma, comprovou-se que, por mais que os moradores tenham conhecimento dos benefícios que a espécie Mangifera 
indica proporciona ao meio urbano, os mesmos não se comprometem ou participam na manutenção dessa espécie.

Lacerda et al. (2010), confirmam em sua pesquisa, o importante papel da população como parceira no sucesso da arborização urbana, onde 39,2\% dos entrevistados colaboram com o desenvolvimento das árvores, com diversas ações, entre elas: 28,9\% executa plantios, $4,1 \%$ não danifica, $27,8 \%$ não maltrata, enquanto que $27,8 \%$ disseram que nada fazem.

Os bairros Guamá e Jurunas foram os bairros que tiveram $100 \%$ das pessoas despreocupadas com a manutenção da Mangifera indica, o que pode estar relacionado à falta de vínculo com a Mangifera indica, ao baixo grau de escolaridade e pouca consciência ambiental. Numa avaliação realizada na Serra João do Vale - Rio Grande do Norte, Lucena e Freire (2014) constataram que a percepção ambiental é quase inexistente, devido ao baixo grau de escolaridade.

Na Figura 10 estão apresentados os tipos de danos nos indivíduos de Mangifera indica percebido pelos entrevistados nos bairros amostrados.

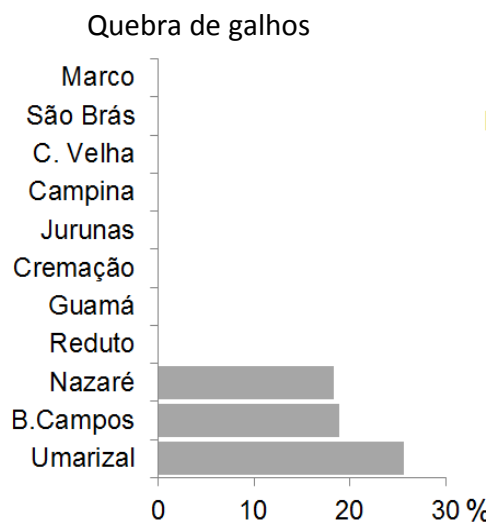

Tutor arrancado

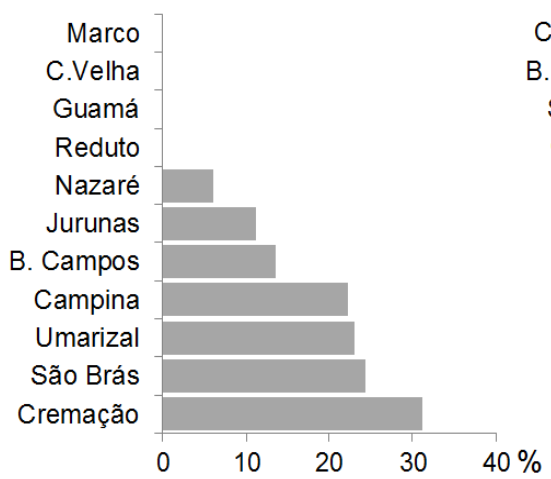

Injúria no caule

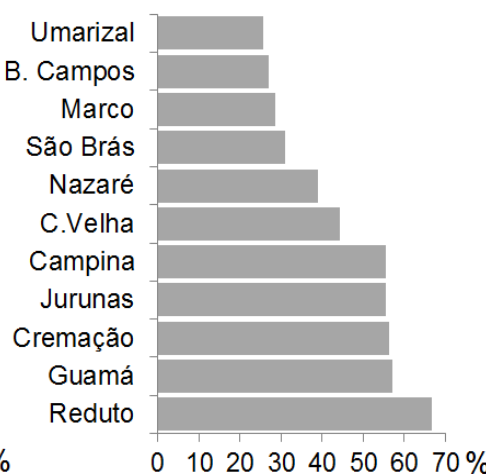

Danos nas raízes

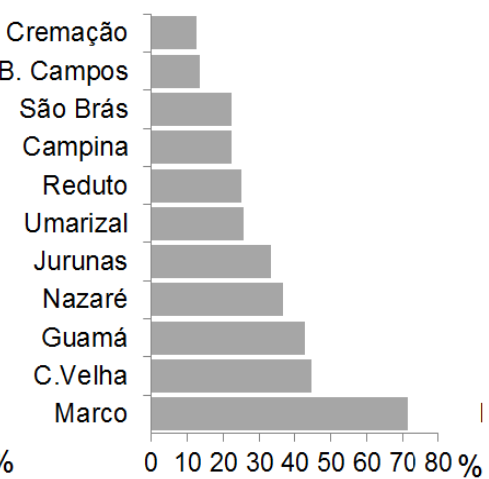

Morte provocada

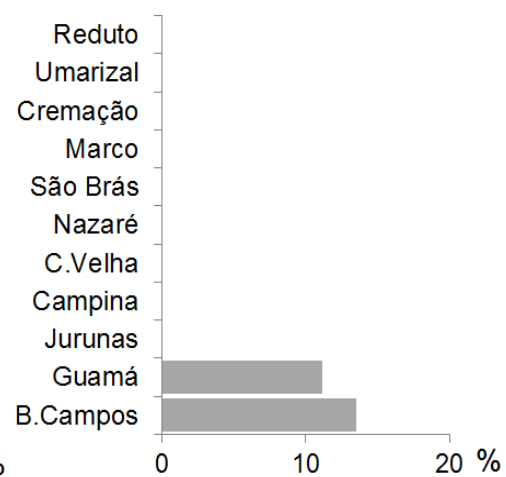

Anelamento

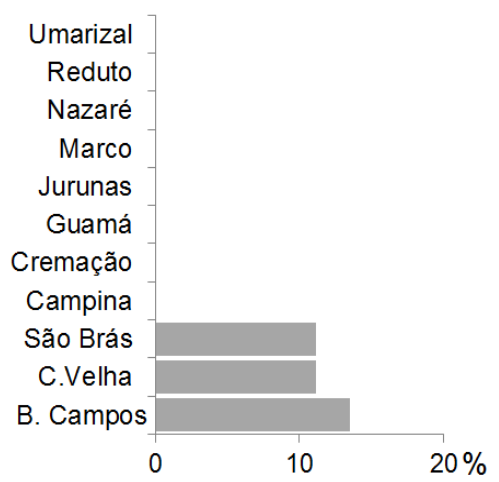

Figura 10. Percepção dos entrevistados quanto aos tipos de danos nos indivíduos de Mangifera indica L. (mangueira) nos bairros do DABEL

Figure 10. Perception of interviewed residents regarding the types of damages to individuals Mangifera indica L. (mango tree) at DABEL neighborhoods 
Os entrevistados observaram vários tipos de danos nos indivíduos de Mangifera indica plantada nas ruas do DABEL. Nos bairros Batista Campos e São Brás foi onde mais se perceberam danos. Dos seis danos evidenciados, os entrevistados do bairro Batista Campos perceberam todos os itens e no Bairro de São Brás, a população detectou cinco danos. Isso pode estar relacionado com as atividades comerciais que cercam esses bairros, seguidas pelas práticas de vandalismo constantes, deixando os moradores mais atentos para os danos que os cercam.

Nota-se que os danos mais detectados pela população do DABEL foram injúria no caule e danos nas raízes. Esse resultado está de acordo com a observação realizada em campo, uma vez que foram detectadas injúrias às raízes provocadas pela alteração do nível do solo.

Gonçalves e Paiva (2006) afirmam que o uso de arame amarrando as árvores ao tutor pode causar danos às mesmas, como estrangulamento e descascamento, com intuito de provocar a sua morte. Enquanto que o anelamento é um dos tipos de danos que é praticado por parte da população das cidades com o objetivo de matar a árvore através do impedimento da passagem da seiva.

Na Figura 11 estão apresentadas as recomendações sugeridas pelos entrevistados nos bairros amostrados.

Em relação a este quesito, observou-se que 53\% dos entrevistados dos 11 bairros amostrados recomendaram a prática de podar a Mangifera indica das ruas. Os bairros que apresentam maior quantidade de Mangifera indica (São Brás, Batista Campos, Umarizal, Marco e Nazaré) foram os que apresentaram maior percentual de percepção quanto à necessidade de poda, somando 49\%. Já os bairros que possuem menor número de Mangifera indica, tais como: Guamá, Cidade Velha, Jurunas, Cremação, Reduto e Campina foram os que melhor perceberam a necessidade de se plantar mais Mangifera indica nas ruas de cada bairro, totalizando $17 \%$. Assim, percebe-se uma relação entre o número de Mangifera indica e cada bairro amostrado, isto é, os moradores dos bairros com mais Mangifera indica perceberam melhor a necessidade de realizar podas com mais frequência, enquanto que os moradores dos bairros com menor número de indivíduos de Mangifera indica perceberam a necessidade de se plantar mais. 

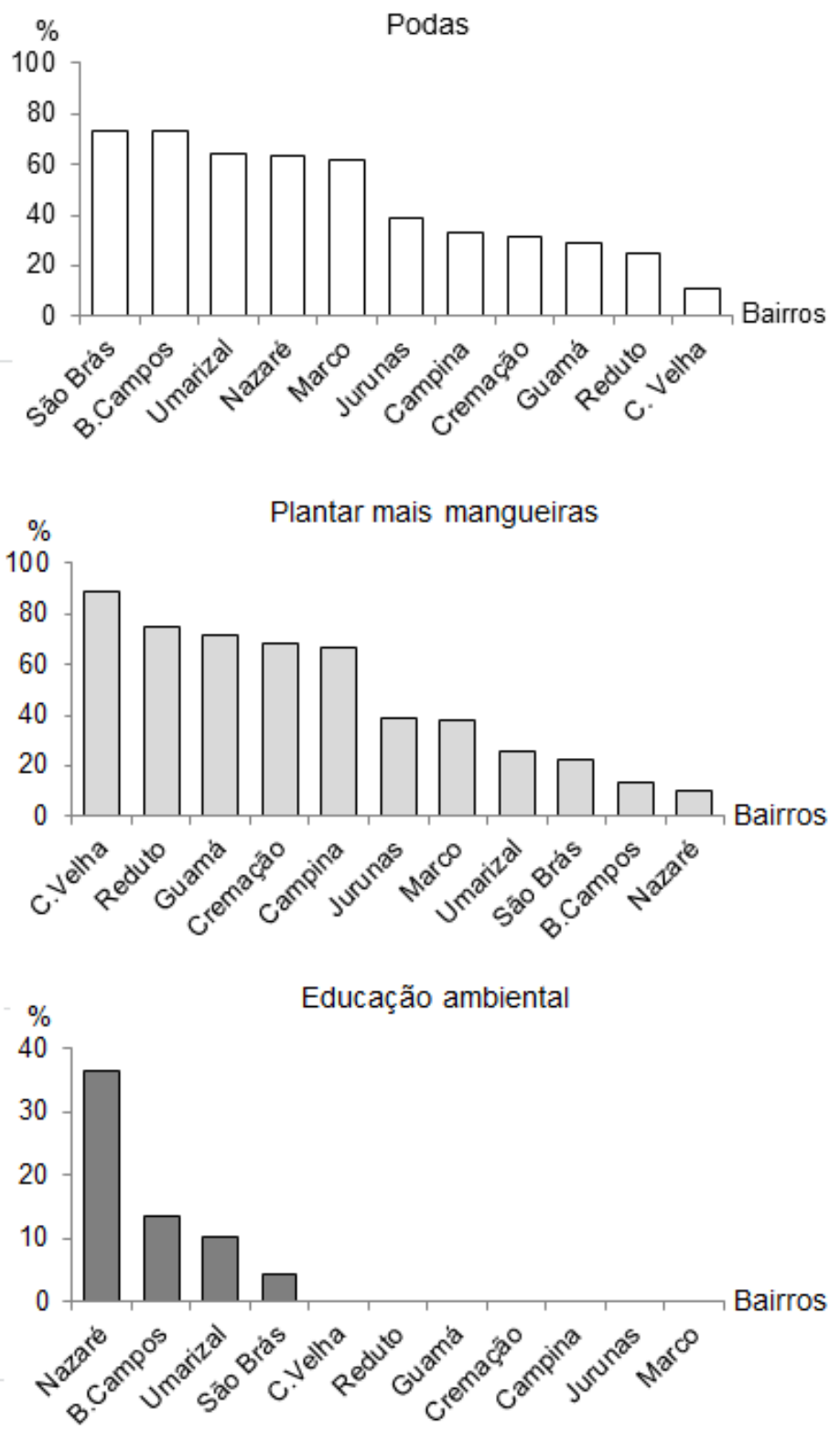

Figura 11. Recomendações dos entrevistados para melhoria da arborização com Mangifera indica L. (mangueira) nos bairros do DABEL

Figure 11. Recommendations of interviewed residents for improving the afforestation with Mangifera indica L. (mango tree) at DABEL neighborhoods

De acordo com Costa e Colesanti (2011), a percepção ambiental é um processo participativo, onde estão integrados fatores sensoriais, valores sociais, culturais e posturas ambientais da população. Desta forma, o estudo da percepção enquanto avaliação e entendimento dos sentimentos e valores são prioritários para tomada de atitudes em relação à arborização. 


\section{CONCLUSÕES}

A população de Belém demonstrou perceber que a arborização tem grande importância por propiciar vários benefícios aos habitantes das cidades, tais como: qualidade de vida, purificação do ar, sombra, abrigo e alimento para avifauna e embelezamento da rua.

Entre os bairros da cidade destacou-se o Umarizal, onde $72 \%$ dos entrevistados atribuíram funções fundamentais da arborização. A população colabora na manutenção, limpando o entorno da Mangifera indica, ligando para SEMMA e recolocando tutores. A pesquisa recomenda que a SEMMA realize o manejo dos indivíduos de Mangifera indica que estão nas ruas, propiciando assim, maior conservação das mesmas.

Os resultados desta pesquisa devem servir para contribuir com o poder público local de maneira a atender aos anseios da população, servindo como base para o desenvolvimento de uma maior sensibilização da população buscando o comprometimento da mesma, evidenciando a importância da arborização visando uma melhor qualidade de vida.

\section{REFERÊNCIAS}

ALRECK, P. L.; SETTLE, R. B. The survey research handbook. New York: McGrawHill/Irwin, 2004. 463p.

CANABRAVA, C. C. R.; MOREIRA, D. S.; ALVES, F. L.; AVELINO, P. N. S.; MELO, T. T. Estudo da percepção ambiental de acadêmicos do curso de ciências biológicas da PUC Minas - Campus coração eucarísticos - Sobre alterações climáticas. Revista Sinapse Ambiental, Betim, v. 4, n. 2., p. 26-47, 2007.

COSTA, R. G. S.; COLESANTI, M. M. A contribuição da percepção ambiental nos estudos das áreas verdes. RA'E GA, Curitiba, v. 22, s. n., p. 238 - 251, 2011.

FERREIRA, E. S.; AMADOR, M. B. M. Arborização urbana: a questão das praças e calçadas no município de Lajedo-PE e a percepção da população. Periódico Eletrônico Fórum Ambiental da Alta Paulista, São Paulo, v. 9, n. 4, p. 59-78, 2013.

GONÇALVES, W.; PAIVA, H. N. Silvicultura urbana: implantação e manejo. Viçosa: Aprenda Fácil, 2006. 203p.

GROSS, A.; DORS, P.; CAMPOS, K. A.; SILVA, A. C.; HIGUCHI, P. Percepção dos moradores e avaliação da arborização em bairros periféricos na cidade de Lages, SC. Revista da Sociedade Brasileira de Arborização Urbana, Piracicaba, v. 7, n. 2, p. 24-36, 2012. 
GUSMÃO, L. H. A. O avanço da verticalização em Belém. Revista Geocartografia digital, Belém, v. 2, s. n., p. $3-5,2014$.

INSTITUTO BRASILEIRO DE GEOGRAFIA E ESTATÍSTICA (IBGE). Belém em dados. Disponível em: <http://www.ibge.gov.br/censo>. Acesso em: 10 set. 2012.

LACERDA, N. P.; SOUTO, P. C.; DIAS, R. S.; SOUTO, L. S.; SOUTO, J. S. Percepção dos residentes sobre a arborização da cidade de São José de Piranhas - PB. Revista da Sociedade Brasileira de Arborização Urbana, Piracicaba, v. 5, n. 4, p. 81-95, 2010.

LORENZI, H.; BACHER, L.; LACERDA, M.; SARTORI, S. Frutas brasileiras e exóticas cultivadas: de consumo in natura. São Paulo: Instituto Plantarum de Estudos da Flora, 2006. 640p.

LOUREIRO, V. R.; BARBOSA, E. J. S. Cidade de Belém e natureza: uma relação problemática?. Periódicos UFPA, Belém, v. 13, n. 1, p. $105-134,2010$.

LUCENA, M. M.; FREIRE, E. M. Percepção ambiental como instrumento de participação social na proposição de área prioritária no semiárido. Revista Internacional Interdisciplinar INTERthesis, Florianópolis, v. 11, n. 1, p. 120 - 147, 2014.

LUZ, L. M.; RODRIGUES, J. E. C. Análise do índice da cobertura vegetal em áreas urbanas: estudo de caso da cidade de Belém - PA. Boletim Amazônico de Geografia, Belém, v. 1, n. 1 , p. $43-57,2014$.

MARIALVA, M. E. A. O Patrimônio Histórico e Cultural: um passeio pela "Cidade das Mangueiras". Revista Turismo, São Paulo, v.1, n.1. p 3- 6, 2006.

MELLAZO, G. C. A percepção ambiental e educação ambiental: uma reflexão sobre as relações interpessoais e ambientais no espaço urbano. Olhares \& Trilhas, Uberlândia, v.4, n. 6 , p. 45-51, 2005.

OLIVEIRA, K. A.; CORONA, H. M. P. A percepção ambiental como ferramenta de propostas educativas e de políticas ambientais. Revista Científica ANAP Brasil, São Paulo, v. 1, n. 1, p. 54-55, 2008.

PIZZIOLO, B. V.; TOSTES, R.; SILVA, K.; ARRUDA, V. M. Arborização urbana: Percepção ambiental dos moradores dos bairros Bom Pastor e Centro da cidade de Ubá/MG. Revista Eletrônica em Gestão, Educação e Tecnologia Ambiental, Santa Maria, v. 18, n. 3, p.1162-1169, 2014.

PORTO, L. P. M.; BRASIL, H. M. S.; SILVA, A. C. P.; REIS, A. F. S.; OLIVEIRA, D. B. D.; FRAZÃO, D. A. C.; SHIMIZU, E. S. C.; ARAGÃO, I. L. G.; SOUSA, J. A. L.; SAITO, L. G. B.; CARVALHO, L. F. M; LEÃO, N. V. M.; ROSAS, A. S. R.; BARBOSA, L. G. B.; SAMPAIO, M. R. G. Manual de orientação técnica da arborização urbana de Belém. Disponível em: < http://ww3.belem.pa.gov.br/www/wp-content/uploads/Manual-de

Arboriza\%C3\%A7\%C3\%A3o-de-Bel\%C3\%A9m.pdf > Acesso em: 18 ago. 2014.

QUADROS, L. S.; FREI, F. Percepção ambiental dos residentes da cidade de Assis - SP com relação à arborização viária da Avenida Rui Barbosa. Revista da Sociedade Brasileira de Arborização Urbana, Piracicaba, v. 4, n. 2, p.16-34, 2009. 
RODRIGUES, T. D.; MALAFAIA, G.; QUEIROZ, S. E. E.; RODRIGUES, A. S. L. Percepção sobre arborização urbana de moradores em três áreas de Pires do Rio - Goiás. Revista de Estudos Ambientais, Blumenau, v.12, n. 2, p. 47-61, 2010.

SECRETARIA MUNICIPAL DE COORDENAÇÃO GERAL DO PLANEJAMENTO E GESTÃO (SEGEP). Conteúdo Belém. Disponível em: < http://www.belem.pa.gov.br/app/c2ms/ $\mathrm{v} /$ ? id=2\&conteudo=4485>. Acesso em: 20 set. 2012.

SILVA, S. B. Belém vai deixando de ser Cidade das Mangueiras. DiárioOnLine. Disponível em: <http://www.diarioonline.com.br/noticias/para/noticia-315424-.html>. Acesso em: 26 mar. 2015.

ZEM, L. M.; BATISTA, D. B. Análise da percepção da população em relação ao vandalismo na arborização viária de Curitiba - PR. Revista da Sociedade Brasileira de Arborização Urbana, Piracicaba, v. 9, n. 3, p.86-107, 2014. 